\title{
INVASION AND ESTABLISHMENT OF HOUSE FLY, MUSCA DOMESTICA (DIPTERA: MUSCIDAE), PARASITES (HYMENOPTERA: PTEROMALIDAE) IN NEW CAGED-LAYER POULTRY HOUSES ${ }^{1}$
}

\author{
By Donald A. Rutz and Richard C. Axtell ${ }^{2}$
}

\begin{abstract}
Muscidifurax raptor, Spalangia undescribed sp. near drosophilae, S. cameroni, Pachycrepoideus vindemiae and Nasonia vitripennis invaded manure at new caged-layer poultry houses near Raleigh, North Carolina within 8 weeks after the chickens were placed in the houses. After these houses were in operation for 16 weeks, Spalangia endius and S. nigroaenea were also recovered. Spalangia nigra was the only parasite species new to the collections at these houses during the 2 nd year of operation (1978). During the 2-year study, $M$. raptor, $P$. vindemiae and $S$. cameroni ranked 1st, 2nd and 3rd, respectively, in relative abundance of all parasites collected. $M$. raptor and $P$. vindemiae were abundant from June through November. S. cameroni was prevalent in late summer and fall, while the other Spalangia species and $N$. vitripennis were most abundant during the summer. Weekly sustained releases of a Florida strain of $S$. endius did not increase house fly pupal parasitism at these poultry houses; only 3 specimens of $S$. endius were recovered during 3 months (August-October) of releases of 18,000 parasites per week.
\end{abstract}

Several indigenous house fly (Musca domestica L.) parasite species, normally active in manure at caged-layer poultry farms, play an important role in managing fly populations (Rutz \& Axtell 1980a). Releases of indigenous parasites may further enhance their effectiveness (Morgan et al. 1975a, b, Olton \& Legner 1975, Pickens et al. 1975, Rutz \& Axtell 1980b).

In order to improve our understanding of the population dynamics of indigenous house fly parasites, we determined the sequence of invasion, relative abundance and seasonal abundance of parasites in manure at new caged-layer poultry houses during their first 2 years of operation. In addition, during the 2 nd year of the study we evaluated the effect of sustained releases of a Florida strain of Spalangia endius Walker on house fly parasitism at these houses.

\section{MATERIALS AND METHODS}

The study was conducted at 2 narrow caged-layer poultry houses. These houses were open-sided

\footnotetext{
${ }^{1}$ Paper No. 6043 of the Journal Series of the North Carolina Agricultural Research Service, Raleigh, NC.

${ }^{2}$ Department of Entomology, North Carolina State University, Raleigh, North Carolina 27650, USA.
}

structures $(40 \mathrm{~m}$ long $\times 3 \mathrm{~m}$ wide; 1000 bird capacity each) with 1 row of 2-tiered wire stairstep cages, 2 or 3 birds per cage, suspended $1-1.5 \mathrm{~m}$ above a dirt floor and running the length of the house along each side of a single concrete aisle. Construction of the houses was completed in March 1977, with chickens being placed in the houses in late April.

The houses were located at a poultry research farm of North Carolina State University near Raleigh in the Piedmont region of the state. This research farm had several broiler houses, a controlled-environment wide-span caged-layer house with a flush manure-removal system and a broilerbreeder house. Although a potential problem, there was little evidence of fly production occurring or having occurred in these existing houses. The principal fly and fly parasite producing areas in the general vicinity appeared to be a beef cattle farm and a dairy farm, both located within $0.5-1.0$ $\mathrm{km}$ of the new poultry houses.

Parasite populations at the new caged-layer houses were monitored from March 1977, approximately 2 months before chickens were placed in the houses, through November 1978 by the pupal bag collection technique. Pupal bags were made of 14-mesh (ca $6 \mathrm{mesh} / \mathrm{cm}$ ) screen and each contained 25 laboratory-reared house fly pupae $(<1$ day old $)$. In 1977,16 bags were positioned weekly in each house on the periphery of the manure at a depth of $5-10 \mathrm{~cm}$ where naturally occuring fly pupation was likely to take place. After being exposed for 7 days, the bags were collected and new bags were positioned similarly in the manure at new locations; 8 bags per house were used in 1978. Parasite populations at the nearby beef and dairy cattle farms were also monitored weekly by the pupal bag technique (5-10 bags per farm per week) from March through June 1977. The exposed pupae from the pupal bags were held in the laboratory for ca $45-60$ days at $26.7{ }^{\circ} \mathrm{C}$ and $60 \pm 10 \% \mathrm{RH}$ to allow time for parasite development and emergence. 
TABLE 1. Sequence of invasion, relative abundance and seasonal abundance of parasitic Hymenoptera that emerged from house fly pupae placed in poultry manure at 2 new narrow caged-layer poultry houses at Research Farm Unit 2, NCSU, Raleigh (1977).

\begin{tabular}{|c|c|c|c|c|c|c|c|c|c|c|c|}
\hline \multirow{2}{*}{ SPECIES } & \multicolumn{10}{|c|}{ \% RELATIVE ABUNDANCE AND (IN PARENTHESES) SEASONAL ABUNDANCE**** } & \multirow{2}{*}{$\begin{array}{l}\text { TOTAL } \\
\text { NO, COL- } \\
\text { LECTED }\end{array}$} \\
\hline & $\begin{array}{l}\text { Mar.- } \\
\text { Apr. }\end{array}$ & May & June & July & Aug. & Sept. & Oct. & Nov. & Dec. & $\underset{\substack{\text { Mean } \\
* * *}}{ }$ & \\
\hline Muscidifurax raptor & & $\begin{array}{c}80.0 \\
(0.2)\end{array}$ & $\begin{array}{l}51.3 \\
(5.2)\end{array}$ & $\begin{array}{c}74.3 \\
(42.4)\end{array}$ & $\begin{array}{c}63.1 \\
(20.0)\end{array}$ & $\begin{array}{c}49.1 \\
(11.1)\end{array}$ & $\begin{array}{c}82.1 \\
(15.1)\end{array}$ & $\begin{array}{l}53.5 \\
(5.9)\end{array}$ & & 66.1 & 2213 \\
\hline Spalangia cameroni & & & $\begin{array}{c}0.4 \\
(0.4)\end{array}$ & & $\begin{array}{c}17.0 \\
(49.4)\end{array}$ & $\begin{array}{c}4.2 \\
(8.7)\end{array}$ & $\begin{array}{c}1.7 \\
(2.9)\end{array}$ & $\begin{array}{c}38.3 \\
(38.6)\end{array}$ & & 7.2 & 241 \\
\hline S. undescribed sp. near drosophilae & & $\begin{array}{c}20.0 \\
(6.7)\end{array}$ & & $\begin{array}{c}1.1 \\
(93.3)\end{array}$ & & & & & & 0.4 & 15 \\
\hline S. endius & & & & & $\begin{array}{c}7.8 \\
(94.8)\end{array}$ & $\begin{array}{c}0.6 \\
(5.2)\end{array}$ & & & & 1.7 & 58 \\
\hline S. nigroaenea & & & & & $\begin{array}{c}7.5 \\
(74.6)\end{array}$ & $\begin{array}{c}2.8 \\
(19.7)\end{array}$ & $\begin{array}{c}1.0 \\
(5.6)\end{array}$ & & & 2.1 & 71 \\
\hline Pachycrepoideus vindemiae & & & $\begin{array}{c}37.2 \\
(11.6)\end{array}$ & $\begin{array}{c}24.6 \\
(42.8)\end{array}$ & $\begin{array}{c}4.6 \\
(4.4)\end{array}$ & $\begin{array}{c}43.3 \\
(29.9)\end{array}$ & $\begin{array}{c}15.2 \\
(8.6)\end{array}$ & $\begin{array}{c}8.2 \\
(2.7)\end{array}$ & & 21.7 & 725 \\
\hline Nasonia vitripennis & & & $\begin{array}{c}11.1 \\
(100.0)\end{array}$ & & & & & & & 0.8 & 25 \\
\hline Total no. parasites collected/month & 0 & 5 & 226 & 1263 & 702 & 501 & 408 & 243 & 0 & & 3348 \\
\hline$\%$ parasitism $\div$ & 0.0 & 0.1 & 7.0 & 39.4 & 17.7 & 15.7 & 10.3 & 7.7 & 0.0 & 13.6 & \\
\hline
\end{tabular}

* Relative abundance values are the percentage of that species out of the total number of parasites (all species) collected each month from 3200 exposed pupae (25 pupae/bag, 16 bags/house/wk, 2 houses).

** Seasonal abundance values are the percentage of the total 10-month collection of that species recovered during that month.

*** Based on the total number of parasites collected over the 10 -month survey period.

$\dagger$ Percentage of exposed house fly pupae from which adult parasites emerged.

In addition to parasite monitoring with pupal bags, attempts were made to collect naturally occurring fly pupae (pupal samples) from the manure at the new poultry houses and nearby beef and dairy cattle farms, but adequate numbers could not be collected regularly. A previous study at caged-layer poultry houses (Rutz \& Axtell $1980 \mathrm{a}$ ) indicated that both the pupal bag and pupal sample parasite monitoring techniques collected similar parasite species. Therefore, the pupal bag technique was considered adequate for monitoring the invasion and occurrence of parasites at the new poultry houses.

Sustained releases of $S$. endius were made weekly during August through October in 1978 at these houses. S. endius was obtained from the Insects Affecting Man and Animals Research Lab, USDA, SEA, in Gainesville, Florida. The parasites were shipped as parasitized pupae which were scheduled to emerge on alternate days, 4 to 8 days after shipment. On the day of their arrival the parasitized pupae were taken to the poultry houses and poured at 8 nearly equidistant locations within each of the houses on the drier peripheral areas of the manure where flies usually pupate. Aliquots of 200 pupae each were taken from each batch of pupae with different scheduled emergence dates and held in the laboratory for 30 days at $26.7{ }^{\circ} \mathrm{C}$ and $60 \pm 10 \% \mathrm{RH}$ to determine the percentage adult emergence and the male:female sex ratio. Parasites emerged from an average of $54 \%$ (range $24-80 \%$ ) of the parasitized pupae, with $71 \%$ being females. With this aliquot information we determined that an average of 18,000 parasites were released each week.

\section{RESULTS AND DISCUSSION}

Seven house fly parasite species, listed here according to their sequence of invasion into new caged-layer poultry houses were collected in 1977 (TABle 1): Muscidifurax raptor Girault \& Sanders, Spalangia undescribed sp. near drosophilae Ashmead (identified by Z. Bouček, British Museum of Natural History), S. cameroni Perkins, Pachycrepoideus vindemiae Rondani, Nasonia vitripennis Walker, S. endius Walker and S. nigroaenea Curtis. No parasites were recovered from the new houses during March and April in the absence of chickens and manure. After the chickens were in the houses and the manure accumulated for about 2 weeks 
TABLE 2. Relative abundance and seasonal abundance of parasitic Hymenoptera that emerged from house fly pupae placed in poultry manure during the 2nd year of operation of 2 new narrow caged-layer poultry houses at Research Farm Unit 2, NCSU, Raleigh (1978).

\begin{tabular}{|c|c|c|c|c|c|c|c|c|c|c|}
\hline \multirow{2}{*}{ SPECIES } & \multicolumn{9}{|c|}{ \% RELATIVE ABUNDANCE AND (IN PARENTHESES) SEASONAL ABUNDANCE***** } & \multirow{2}{*}{$\begin{array}{l}\text { TOTAL } \\
\text { NO. COL- } \\
\text { LECTED } \\
\end{array}$} \\
\hline & $\begin{array}{l}\text { Jan.-- } \\
\text { Apr. }\end{array}$ & May & June & July & Aug. & Sept. & Oct. & Nov. & $\begin{array}{c}\text { Mean } \\
* * *\end{array}$ & \\
\hline Muscidifurax raptor & & & $\begin{array}{l}55.3 \\
(9.8)\end{array}$ & $\begin{array}{c}75.6 \\
(50.4)\end{array}$ & $\begin{array}{c}57.7 \\
(22.2)\end{array}$ & $\begin{array}{c}32.7 \\
(8.1)\end{array}$ & $\begin{array}{l}11.8 \\
(4.7)\end{array}$ & $\begin{array}{l}27.3 \\
(4.8)\end{array}$ & 48.8 & 1109 \\
\hline Spalangia cameroni & & & $\begin{array}{c}0.5 \\
(0.6)\end{array}$ & $\begin{array}{c}0.1 \\
(0.6)\end{array}$ & $\begin{array}{c}9.4 \\
(24.8)\end{array}$ & $\begin{array}{c}27.3 \\
(46.6)\end{array}$ & $\begin{array}{c}3.4 \\
(9.3)\end{array}$ & $\begin{array}{c}14.9 \\
(18.0)\end{array}$ & 7.1 & 161 \\
\hline S. endiust & & & $\begin{array}{c}2.5 \\
(62.5)\end{array}$ & & $\begin{array}{c}0.5 \\
(25.0)\end{array}$ & & $\begin{array}{c}0.2 \\
(12.5)\end{array}$ & & 0.4 & 8 \\
\hline S. nigra & & & & & $\begin{array}{c}1.9 \\
(100.0)\end{array}$ & & & & 0.4 & 8 \\
\hline S. nigroaenea & & & $\begin{array}{c}0.5 \\
(14.3)\end{array}$ & $\begin{array}{c}0.1 \\
(14.3)\end{array}$ & $\begin{array}{c}0.7 \\
(42.8)\end{array}$ & $\begin{array}{c}0.4 \\
(14.3)\end{array}$ & $\begin{array}{c}0.2 \\
(14.3)\end{array}$ & & 0.3 & 7 \\
\hline Pachycrepoideus vindemiae & & $\begin{array}{r}100.0 \\
(0.1)\end{array}$ & $\begin{array}{c}16.2 \\
(3.6)\end{array}$ & $\begin{array}{c}20.2 \\
(16.5)\end{array}$ & $\begin{array}{c}29.8 \\
(14.1)\end{array}$ & $\begin{array}{c}39.6 \\
(12.1)\end{array}$ & $\begin{array}{c}84.3 \\
(41.2)\end{array}$ & $\begin{array}{c}57.7 \\
(12.4)\end{array}$ & 39.6 & 901 \\
\hline Nasonia vitripennis & & & $\begin{array}{c}24.9 \\
(62.0)\end{array}$ & $\begin{array}{c}4.0 \\
(38.0)\end{array}$ & & & & & 3.5 & 79 \\
\hline $\begin{array}{l}\text { Total no. parasites collected } / \text { month } \\
\% \text { parasitismt† }\end{array}$ & $\begin{array}{l}0 \\
0.0\end{array}$ & $\begin{array}{l}1 \\
0.1\end{array}$ & $\begin{array}{r}197 \\
12.3\end{array}$ & $\begin{array}{r}740 \\
38.4\end{array}$ & $\begin{array}{r}426 \\
26.6\end{array}$ & $\begin{array}{r}275 \\
17.2\end{array}$ & $\begin{array}{r}440 \\
22.9\end{array}$ & $\begin{array}{r}194 \\
16.9\end{array}$ & 22.3 & 2273 \\
\hline
\end{tabular}

* Relative abundance values are the percentage of that species out of the total number of parasites (all species) collected each month from 1600 exposed pupae (25 pupae/bag, 8 bags/house/wk, 2 houses). month.

** Seasonal abundance values are the percentage of the total 11-month collection of that species recovered during that

*** Based on the total number of parasites collected over the 11-month survey period.

$\dagger 18,000 \mathrm{~S}$. endius released weekly from August through October.

$t \dagger$ Percentage of exposed house fly pupae from which adult parasites emerged.

(May), M. raptor and $S$. undescribed sp. near drosophilae parasitized $0.1 \%$ of the exposed fly pupae. Parasitism increased to $7 \%$ in June with $M$. raptor, $S$. cameroni, $P$. vindemiae and $N$. vitripennis now active in the manure. S. endius and $S$. nigroaenea were first observed in August, approximately 3 months after chickens were placed in the houses.

$M$. raptor was recovered from pupal bags placed at the nearby beef and dairy cattle farms, indicating that those farms were possible sources of at least 1 species of fly parasite invading the new poultry houses. Because of difficulty in recovering the exposed pupal bags, parasite monitoring was discontinued at these nearby farms in June.

$M$. raptor, with a mean relative abundance of $66.1 \%$, was the most abundant parasite collected at the new poultry houses. $P$. vindemiae was second in overall relative abundance, followed by $S$. $\mathrm{ca}$ meroni, S. nigroaenea, S. endius, $N$. vitripennis and $S$. undescribed sp. near drosophilae.

With regards to seasonal abundance (TABLE 1), $M$. raptor and $P$. vindemiae were most abundant in July but both species were prevalent during June through November. S. cameroni was abundant in late summer and fall, while $S$. endius and $S$. nigroaenea were most abundant in August.

Parasitism increased from $0.1 \%$ in May to a high of $39.4 \%$ in July, followed by a steady decrease to $7.7 \%$ in November with an overall average of $13.6 \%$ (TABLE 1). No parasites emerged from pupae exposed in December.

In January of 1978 the old chickens were removed and new chickens were placed in the houses. During this same period, the manure was partially cleaned out, leaving a $15-20 \mathrm{~cm}$ manure base as a refuge for overwintering parasites.

During the 2nd year of operation, no parasites emerged from pupae exposed during January through April and only 1 species ( $P$. vindemiae) was recovered from the pupae exposed during May (TABLE 2). M. raptor, S. cameroni, $P$. vindemiae, and N. vitripennis, as in 1977, were active in the manure in June. In 1978, however, a few S. endius and S. nigroaenea were also collected in June, 2 months before they were observed in the manure in 1977.

As in 1977, M. raptor, $P$. vindemiae and S. cameroni were, respectively, the 1 st, 2 nd and $3 \mathrm{rd}$ most abundant parasite species collected (TABLE 2). N. 
TABLE 3. Fly populations at 2 new (in 1977) narrow caged-layer poultry houses at Research Farm Unit 2, NCSU, Raleigh.

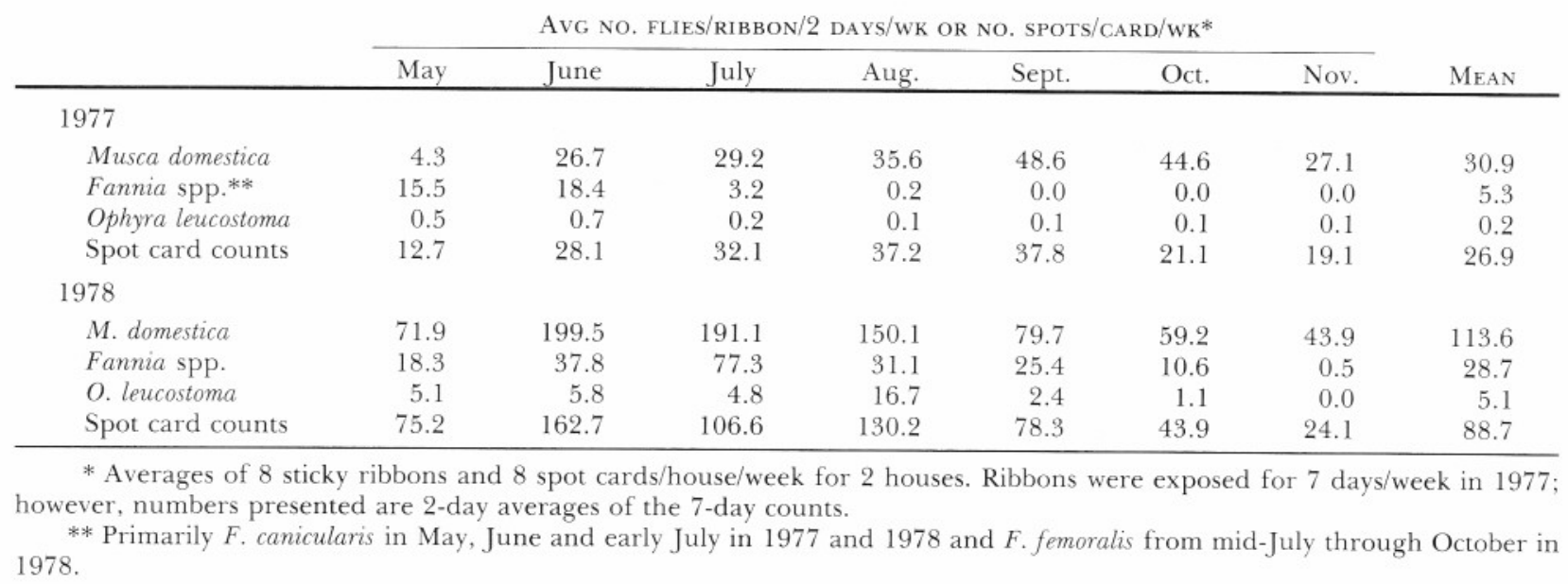

vitripennis, S. endius, S. nigra Latreille, and S. nigroaenea were also collected. S. nigra was new in the collections in 1978; however, no specimens of S. undescribed sp. near drosophilae were collected in 1978 .

Seasonal abundance of the different parasite species in 1978 (TABLE 2) was similar to that observed both in these houses in 1977 and at cagedlayer poultry farms in operation for several years in the same geographic region (Rutz \& Axtell 1980a). $M$. raptor and $P$. vindemiae were prevalent during June through November, with $M$. raptor being most abundant in July; however, in 1978, $P$. vindemiae was most abundant in October. S. cameroni was again abundant during August through November. Too few (7-8) S. endius, S. nigra and $S$. nigroaenea were recovered to justify any statement about their seasonal abundance. $N$. vitripennis was only collected in June and July. The total number of parasites collected in 1978 was less than that collected in 1977 because the number of pupal bags placed in each house was reduced from 16 per week in 1977 to 8 per week in 1978 . However, the average number of parasites collected per bag was greater in 1978 than 1977.

Parasitism rates in 1978 (TABLE 2) were similar to those observed in 1977 during the first 7 months of the year but were generally higher in 1978 during August through November. Parasitism in 1978 again peaked in July, with an overall average (May through November) of $22.3 \%$. The July parasitism peaks in 1977 and 1978 and overall average parasitism in 1978 at these new houses were also similar to parasitism $(42.4 \%$ peak parasitism in July and an overall average of $26.5 \%$ ) observed at caged-layer poultry farms in operation for several years in the same geographic region (Rutz \& Axtell 1980a).

During the 2-year period of parasite monitoring, there were appreciable fly populations at the new poultry houses, which should have been sufficient to sustain indigenous parasite populations. Musca domestica was the predominant fly at the poultry houses in 1977 and 1978 (TABLE 3). Fannia canicularis (L.), F. femoralis Stein and Ophyra leucostoma (Wiedemann) were also collected. Fly populations all generally increased 4- to 5-fold from 1977 to 1978.

Sustained releases of $S$. endius, which were initiated during the 1st week of August and continued through October, had no apparent effect on house fly pupal parasitism (TABLE 2). Only 3 specimens of $S$. endius were recovered from the exposed pupae during the release period. Since the parasitized pupae were poured on the surface of the manure (a recommended procedure for release of commercially available parasites), they were susceptible to predators, particularly ants. Ants were occasionally observed in and on the poultry manure; however, they did not appear numerous enough to be a significant threat to the parasitized pupae. In addition, in our release studies with $M$. raptor (Rutz \& Axtell 1980b), we used this same method of parasite release with no apparent predation problem. Although predation is a potential problem in need of consideration when parasites are released, it is doubtful that predators greatly affected the performance of $S$. endius in this investigation. Biased sampling techniques were also considered but dismissed as a possible cause for the failure of these $S$. endius releases. In a statewide house fly parasite survey in which we 
used both pupal bag and pupal sample parasite monitoring techniques (Rutz \& Axtell 1980a), we found that the pupal sample technique, i.e., collection of naturally occurring pupae from the poultry manure, produced relatively more Spalangia than the pupal bag technique; however Spalangia specimens were readily collected by both monitoring techniques. In the present study, large numbers of Spalangia (primarily S. cameroni) were recovered with pupal bags in both 1977 and 1978 . This indicates that the low numbers of $S$. endius in the collections both before and after the releases were initiated were not due to biased sampling techniques but due to their absence in the manure. Legner \& Olton (1971) and Tingle \& Mitchell (1975) emphasized the need for house fly parasites to be climatically adapted to the area where releases are to be made. It is possible that climatic conditions in Florida and North Carolina were dissimilar enough to adversely affect the Florida strain of $S$. endius when released in North Carolina. Our field conditions (climatic and/or habitat) may have greatly reduced or even prevented adult emergence from the parasitized pupae (adult emergence, observed only in the laboratory, averaged $54 \%$ ) or possibly the parasites, once emerged, failed to engage in activities necessary for parasitism. It is also possible that the colonization of the Florida strain reduced its adaptation to field conditions. Whatever the cause(s), the failure of our parasite release experiment demonstrates the need for more data on the factors affecting the efficacy of laboratory-reared parasites for house fly control.
Acknowledgments. We than Dr E. F. Legner of the Division of Biological Control, University of California, Riverside and Dr Z. Bouček of the British Museum of Natural History, London for their help in identification of specimens; and Dr R. S. Patterson and Dr P. B. Morgan of the Insects Affecting Man and Animals Research Laboratory, USDA, SEA, Gainesville, Florida for furnishing $S$. endius used in the sustained releases; and T. D. Edwards and N. H. Newton of this laboratory for their assistance in conducting the study.

\section{LITERATURE CITED}

Legner, E. F. \& G. S. Olton. 1971. Distribution and relative abundance of dipterous pupae and their parasitoids in accumulations of domestic animal manure in the southwestern United States. Hilgardia 40: 505-35.

Morgan, P. B., R. S. Patterson, G. C. LaBrecque, D. E. Weidhaas \& A. Benton. 1975a. Suppression of a field population of houseflies with Spalangia endius. Science 189: 38889.

Morgan, P. B., R. S. Patterson, G. C. LaBrecque, D. E. Weidhaas, A. Benton \& T. Whitefield. 1975b. Rearing and release of the house fly pupal parasite Spalangia endius Walker. Environ. Entomol. 4: 609-11.

Olton, G. S. \& E. F. Legner. 1975. Winter inoculative releases of parasitoids to reduce houseflies in poultry manure. $J$. Econ. Entomol. 68: 35-38.

Pickens, L. B., R. W. Miller \& M. M. Centala. 1975. Biology, population dynamics, and host finding efficiency of Pachycrepoideus vindemiae in a box stall and a poultry house. Environ. Entomol. 4: 975-79.

Rutz, D. A. \& R. C. Axtell. 1980a. House fly (Musca domestica) parasites (Hymenoptera:Pteromalidae) associated with poultry manure in North Carolina. Environ. Entomol. (in press).

1980b. Sustained releases of Muscidifurax raptor (Hymenoptera:Pteromalidae) for house fly (Musca domestica) control in two types of caged-layer poultry houses. Environ. Entomol. (in press).

Tingle, F. C. \& E. R. Mitchell. 1975. Seasonal reproduction of Muscidifurax raptor and Spalangia endius under simulated Florida conditions. Environ. Entomol. 4: 383-84. 